\title{
CALidAd de la REPRESENTACión POLÍTICA $Y$ TAMAÑO DE LAS CIRCUNSCRIPCIONES ELECTORALES: UNA COMPARACIÓN DE LAS ASAMBLEAS PANAMEÑAS DE 1945 Y 1999*
}

\author{
Carlos Guevara Mann \\ Florida State University, Panamá
}

\begin{abstract}
Resumen
En Panamá, como en otros países de la región, la representación política atraviesa una grave crisis. Este artículo arguye que la falta de idoneidad de los representantes explica parcialmente el fenómeno. Con base en los argumentos de James Madison y Richard Katz, la falta de idoneidad puede explicarse, en alguna medida, como resultado del tamaño reducido de las circunscripciones electorales. La comparación entre los diputados elegidos en 1945 y 1999 concluye que en 1945, la organización de los comicios con base en circuitos provinciales y una gran circunscripción nacional contribuyó a producir la elección de individuos mejor calificados para ejercer funciones representativas que en 1999, cuando los legisladores fueron escogidos en circuitos municipales y submunicipales, según lo dispone la constitución vigente.

Abstract

As in other countries in the region, political representation is in crisis in Panama. This article argues that part of the phenomenon is a result of representatives' lack of qualifications. Based on arguments by James Madison and Richard Katz, the reduced size of Panama's electoral districts may explain, at least partially, this lack of qualifications. A comparison between Assembly members elected in 1945 and 1999 concludes that in 1945, provincial electoral districts and one national constituency contributed to return more qualified representatives than in 1999, when legislators were elected in municipal and sub-municipal constituencies, as prescribed by the constitution currently in force
\end{abstract}

PALABRAS CLAVE • Representación • Clientelismo • Circunscripción Electoral • Sistema Electoral - Tamaño de Distrito

* $\quad$ Este trabajo está basado en "Forsaken Virtue: An Analysis of the Political Behavior of Panamánian Legislators, 19841999", tesis presentada por el autor para optar al Doctorado (PhD) en Gobierno y Relaciones Internacionales en la Universidad de Notre Dame, Indiana, Estados Unidos de América en enero de 2001 y fue presentada en el Sexto Congreso Centroamericano de Historia, celebrado en Panamá entre el 22 y 26 de julio de 2002. El autor agradece los comentarios y sugerencias de Gloria Guardia, Aníbal Pérez Liñán, Guillermo Sánchez Borbón y un evaluador anónimo de la Revista de Ciencia Política. 


\section{LA REPRESENTACIÓN DEMOCRÁTICA Y SUS VENTAJAS}

El sistema democrático se considera superior a otros regímenes políticos porque es el único que permite la participación de la ciudadanía en la toma de decisiones que afectan a la comunidad. Esa participación se fundamenta en la noción de igualdad política, que reconoce la autonomía reflexiva de la cual están dotados todos los seres humanos (Dahl, 1989). También se lo considera superior pues en teoría, a través de la representación democrática, la comunidad puede asignar las funciones del gobierno al componente más talentoso y mejor calificado de la sociedad. Esta visión de la democracia tiene sus orígenes en los escritos de John Madison (1987 [1787]), uno de los fundadores de los Estados Unidos de América, quien considera que la representación democrática constituye un método para mejorar la calidad del gobierno popular. El objetivo de Madison fue diseñar y promover un sistema que seleccionase, a través de medios democráticos, a "guardianes idóneos de la cosa pública" (proper guardians of the public weal). Sobre el particular, uno de los ensayos del Federalist señala lo siguiente:

The aim of every political constitution is, or ought to be, first to obtain for rulers men who possess most wisdom to discern, and most virtue to pursue, the common good of the society; and in the next place, to take the most effectual precautions for keeping them virtuous whilst they continue to hold their public trust (The Federalist No. 57, citado en Epstein, 1984: 154) ${ }^{1}$.

Según Madison, la democracia representativa es superior a la democracia directa, pues la representación democrática hace posible conseguir, a través de medios democráticos, el antiguo y deseable ideal republicano del gobierno por el componente más virtuoso de la sociedad, para beneficio de la comunidad. Al requerir la participación directa de cada miembro de la comunidad en el ejercicio de las funciones de gobierno, la democracia directa somete a la república al riesgo que el elemento corrupto de la sociedad -que inevitablemente existe en toda comunidad políticalogre imponerse y corrompa al Estado. La democracia representativa permite que la ciudadanía filtre este elemento a través de elecciones democráticas. El debate público libre y el requisito de rendición de cuentas que forman parte del sistema democrático, hacen sobresalir la virtud y exponen los vicios al escrutinio de la comunidad.

En la búsqueda de este objetivo -y para refutar la tesis de quienes sostenían que un Estado democrático de grandes proporciones geográficas y considerable población es inviable- Madison considera que las circunscripciones electorales de mayor población -las "grandes repúblicas"son más adecuadas que las unidades electorales de tamaño reducido:

As each representative will be chosen by a greater number of citizens in the large than in the small republic, it will be more difficult for unworthy candidates to practise with success the vicious arts, by which elections are too often carried; and the suffrages of the people being

"El objetivo de toda constitución política es o debe ser, primeramente, seleccionar como gobernantes a individuos que posean la mayor sabiduría para discernir y la mayor virtud para procurar el bien común de la sociedad, y seguidamente, tomar las precauciones más efectivas para que se mantengan virtuosos mientras ejercen la confianza pública" (traducción del autor). 
more free, will be more likely to centre in men who possess the most attractive merit, and the most diffusive and established characters (Madison, The Federalist No. 10) ${ }^{2}$.

El razonamiento de Madison es claro. El sufragio tiende a ser "más libre" en distritos electorales de mayor población en vista de que es más difícil practicar, en gran escala, los vicios que señala, tales como la compra de votos. También puede presumirse que en circunscripciones más grandes los vínculos y compromisos que emanan de relaciones personales o "clientelistas" son menos prevalecientes, por lo que los ciudadanos tienen mayor libertad para emitir sus votos a conciencia ${ }^{3}$. Otra ventaja de las circunscripciones electorales de mayor población es que, como lo señala Madison, "si la proporción de individuos idóneos no es menor en la república grande que en la pequeña", habrá más opciones para efectuar un escogimiento de representantes calificados en los circuitos de mayor población que en los de menor número de habitantes (Madison, The Federalist No. 10).

En oposición a este punto de vista podría argüirse que la elección de representantes en distritos electorales pequeños -esto es, de poca población- redunda una relación más estrecha entre el representante y el elector, lo que a su vez se traduce en una mayor responsabilidad y una mejor rendición de cuentas (accountability). Este estudio, sin embargo, sostiene que la tesis de Madison sobre la inconveniencia de las "pequeñas repúblicas" es válida cuando un sistema de representación sobre la base de circuitos electorales de reducido tamaño coincide con los siguientes factores:

1. Una arraigada tradición de particularismo4;

2. Bajo contenido ideológico del debate político;

3. Una marcada desigualdad en la distribución de los recursos, lo que produce mayor demanda de bienes públicos y convierte el voto en una especie de "moneda" para la adquisición de estos bienes por parte de grupos marginados, reforzando así el elemento clientelista de la tradición particularista.

Bajo estas circunstancias, un sistema electoral basado en distritos pequeños con predominio de población marginada, claramente refuerza la tendencia clientelista y disminuye las posibilidades para la elección de representantes competentes. Para los propósitos que nos ocupan, podríamos argumentar que un distrito electoral pequeño, o de reducido tamaño, es aquel que contiene una población inferior al $5 \%$ del número total de habitantes del Estado.

2 "Como quiera que los representantes son elegidos por un mayor número de ciudadanos en la república grande que en la pequeña, es más difícil que en las repúblicas grandes los candidatos indignos practiquen con éxito los vicios mediante los cuales se celebran frecuentemente las elecciones; y al ser por ello más libres los sufragios del pueblo, mayores posibilidades hay de que dichos sufragios se dirijan a los individuos que poseen los méritos más atractivos y las personalidades más amplias y bien constituidas" (traducción del autor).

Agradezco esta observación de Martha Merritt, de la Universidad de Notre Dame.

$4 \quad$ Particularismo es el comportamiento de servidores públicos que se orienta a la satisfacción de intereses particulares (en oposición al bien común). El particularismo comprende otros comportamientos como el clientelismo, término que se refiere a relaciones entre "patrones" y "clientes" políticos cuyas características decisivas son las siguientes: condición y reciprocidad desiguales, naturaleza informal y carácter personal (Mainwaring, 1999: 179, 177). 


\section{LA ASAMBLEA NACIONAL HASTA 1968}

Panamá es un caso de estudio que apunta hacia la validez de este razonamiento. A lo largo de la historia, el clientelismo ha tenido una preponderancia significativa en la determinación de los desenlaces electorales en Panamá. Además, el contenido programático de las candidaturas ha sido tradicionalmente débil. Así lo subrayan dos de los más conocidos estudios de la cultura política panameña (Biesanz y Biesanz, 1955; Janson Pérez, 1993).

En cuanto a la distribución de los recursos, de acuerdo con un estudio del Ministerio de Economía y Finanzas (1997: 7), "la distribución de ingresos en Panamá se caracteriza por un grado de desigualdad que está entre los más altos de América Latina y el mundo. El coeficiente de Gini de desigualdad en 1997 se estimó en 0.60, identificando así a Panamá conjuntamente con Brasil como los países con la peor distribución de ingreso de América Latina". Según el mismo informe, "aunque el ingreso promedio por habitante en Panamá está por encima del nivel de la mayoría de los países" de la región, "por el alto grado de desigualdad persiste una pobreza profunda" que afecta al 42 por ciento de la población, principalmente en las áreas rurales, donde se elige una porción determinante de la cámara legislativa ${ }^{5}$.

En Panamá, pues, coinciden actualmente un sistema electoral en el que predominan las circunscripciones electorales de reducida población con los factores socioeconómicos y culturales antes señalados. La reducción del tamaño de los circuitos electorales fue una de las innovaciones del régimen militar que gobernó entre 1968 y 1989.

Entre la fundación de la Segunda República de Panamá en $1903^{6}$ y el golpe militar de 1968, la función legislativa panameña radicó en la Asamblea Nacional, corporación unicameral que constaba inicialmente de 32 diputados provinciales. El número de integrantes, que bajó a 27 en 1906, aumentó progresivamente hasta 1952, cuando fueron elegidos 53 diputados. Tras la reforma constitucional de 1956, el número de miembros bajó a 42 en 1964 y 1968 (Sánchez González, 2004).

La primera cámara representativa, elegida como Convención Constituyente en diciembre de 1903, se transformó en Asamblea Nacional tras expedir la constitución política del nuevo Estado y elegir al primer Presidente de la República, Manuel Amador Guerrero, en febrero de 1904. En 1906 se eligió una nueva Asamblea, que fue renovada en 1910. Luego de la primera elección de diputados en 1903, la Asamblea Nacional se renovó mediante el voto popular en 16 ocasiones hasta 1968: 1906, 1910, 1914, 1918, 1924, 1928, 1932, 1936, 1940, 1945, 1948, 1952, 1956, 1960, 1964 у 1968.

En el lapso señalado, hubo una breve interrupción en el funcionamiento de dicha corporación, entre 1944 y 19467. Como solución a la crisis política que aquejaba al país, el 29 de diciembre de 1944 el

En 1999, se eligió a 26 legisladores en circuitos llamados "uninominales", esto es, circunscripciones que por su reducida población sólo eligen un legislador. Dicho número representa el $37 \%$ de la Asamblea Legislativa. Otros 45 legisladores fueron seleccionados en circuitos "plurinominales", que eligen un mínimo de dos y un máximo de seis legisladores, dependiendo del número de habitantes con que cuentan.

La Primera República, el Estado de Panamá, estuvo en vigencia entre 1840 y 1841.

Agradezco esta observación de Ricardo Arias Calderón, ex Vicepresidente de la República. En 1951, hubo otro intento, esta vez infructuoso, de clausurar la Asamblea Nacional. En mayo de ese año, el presidente Arias Madrid emitió un decreto que pretendía disolver la Asamblea y reemplazar la constitución de 1946 con la de 1941. La movilización ciudadana contra esta medida obligó al presidente a dejar sin efecto su decreto. La Asamblea Nacional resolvió entonces enjuiciar al presidente Arias Madrid por violación de la constitución. Tras su suspensión del cargo y enjuiciamiento, fue destituido el 25 de mayo de 1951. Ver Fábrega y Boyd Galindo, 1981: 340-45; Pizzurno y Araúz, 1996: 369-73. 
Presidente Ricardo Adolfo de La Guardia emitió un decreto que dejó sin efecto la constitución de 1941, disolvió la Asamblea Nacional y convocó a la elección de una Asamblea Nacional Constituyente ${ }^{8}$.

Los diputados a esta convención fueron elegidos en mayo de 1945, mediante un sistema de representación proporcional ${ }^{9}$, en circunscripciones provinciales, a las que por primera y única vez en la historia panameña se agregó un circuito nacional. La Asamblea elegida se instaló el 15 de junio de 1945, fecha en la que la corporación escogió como Presidente Provisional de la República a Enrique Jiménez, en reemplazo del Presidente de La Guardia (Moscoso, Cabezas y Aguilera, 1945: 13-17). Después de dictar una nueva constitución política, el 1 de marzo de 1946 la Convención renunció al ejercicio del poder constituyente y se transformó en Asamblea Nacional. Asumió entonces facultades legislativas normales de acuerdo con la constitución de 1946, que ejerció hasta el 30 de septiembre de $1948^{10}$.

Entre 1904 y 1944, bajo los estatutos constitucionales de 1904 y 1941, la Asamblea Nacional se reunía cada dos años por un período de tres meses. La constitución de 1946 estableció reuniones anuales de cuatro meses de duración y asignó importantes funciones a la cámara, entre ellas las de determinar la organización y estructura de la administración estatal, el tamaño de las fuerza de seguridad, la administración de la deuda pública, la aprobación de los contratos gubernamentales, la planificación de obras públicas, el escrutinio de las cuentas nacionales y el nombramiento del procurador general de la Nación. Estas funciones se añadieron a las tradicionales facultades legislativas, fiscalizadoras y nominadoras confiadas a la Asamblea Nacional en 1904 y 1941.

\section{DICTADURA, CLIENTELISMO Y CIRCUNSCRIPCIONES ELECTORALES}

Tras acceder al poder en 1968, mediante un golpe de Estado, la dictadura castrense clausuró la Asamblea Nacional, que entonces constaba, como se indicó anteriormente, de 42 diputados provinciales. El Órgano Ejecutivo, controlado por los militares, ejerció directamente el poder legislativo hasta 1972, cuando una nueva constitución dispuso la creación de la "Asamblea Nacional de Representantes de Corregimientos", compuesta por un representante de cada uno de los corregimientos del país.

En Panamá, el corregimiento es la división administrativa más básica. La República está constituida por provincias y comarcas indígenas, que se dividen en distritos municipales y éstos, a su vez,

8 Una de las debilidades del proceso que condujo al escogimiento de los diputados de 1945 fue la exclusión de los sectores fieles al liderazgo del presidente Arnulfo Arias Madrid, depuesto en 1941. Luego del derrocamiento del presidente Arias Madrid, su sucesor de hecho, el presidente de La Guardia, asumió la dirigencia del partido encabezado por el defenestrado mandatario, el Partido Nacional Revolucionario (PNR).

9 La fórmula utilizada consiste en la distribución de escaños por cuociente, medio cuociente y residuo. Con algunas variaciones, el sistema se usó para la elección de diputados en Panamá entre 1928 y 1968. Luego del golpe militar de 1968, el sistema fue adoptado nuevamente tras la reforma constitucional de 1983. Se ha empleado para la elección de legisladores desde entonces, con algunas variaciones que menoscaban la proporcionalidad del sistema. Ver Eduardo Valdés Escoffery, "Evolución de los sistemas electorales".

10 En julio de 1948, esta misma Asamblea resolvió reasumir el ejercicio del poder constituyente que le fue encomendado en 1945, dejar sin efecto los resultados de las elecciones celebradas en mayo, que ganó Arnulfo Arias Madrid y designar a un nuevo presidente provisional, Henrique de Obarrio. La Corte Suprema de Justicia, sin embargo, declaró inconstitucionales estas resoluciones. La nueva Asamblea Nacional, elegida también en mayo, se instaló el 1 de octubre de 1948. Ver República de Panamá, Asamblea Nacional de Panamá, 1948; Pizzurno y Araúz, 1996: 314-17, 321-24, 343. 
en corregimientos. Hasta 1968, en cada municipio funcionaba un concejo (conocido en otras jurisdicciones como cabildo o ayuntamiento), constituido por concejales, los cuales eran elegidos mediante elección proporcional en distritos únicos municipales. Cuando los concejos fueron restituidos en 1972, el distrito único municipal y la fórmula proporcional para la elección de concejales fueron sustituidos por circunscripciones submunicipales (corregimientos), cada una de las cuales elegía a un representante, de acuerdo con el sistema mayoritario. El representante elegido mediante esta nueva fórmula actuaba en varios escenarios: como presidente de la junta comunal de su corregimiento, miembro del concejo municipal, integrante de los nuevos "Consejos Provinciales de Coordinación" y miembro de la Asamblea Nacional de Representantes de Corregimientos.

Un rasgo significativo del nuevo sistema fue la drástica disminución del tamaño de las unidades electorales. Casi la totalidad de los nuevos circuitos tenía menos habitantes que los círculos electorales del régimen anterior. La mayoría tenía alrededor de mil votantes y, en algunos casos, el número de electores apenas excedía los cien (Koster y Sánchez, 1990: 214). Aunque el régimen militar adujo que el cambio instituyó un verdadero "poder popular" en Panamá y lo justificó por la necesidad de entregar el poder legislativo a "los líderes más representativos de la comunidad" (Labrut, 1982: 156), el nuevo sistema violaba las nociones fundamentales de la igualdad política (Still, 1981). En una columna de opinión publicada en La Estrella de Panamá (6 de octubre de 1978), el ex diputado Francisco Linares ilustró la desigualdad del sistema mediante la comparación entre dos corregimientos con igual representación en la Asamblea Nacional de Representantes de Corregimientos: Por un lado, el corregimiento de Playa Chiquita, en la Provincia de Colón, con 32 electores y, por otra, el corregimiento de Calidonia, en la ciudad de Panamá, con 21,595 votantes ${ }^{11}$.

Pese al alegato, la nueva constitución entregó el poder legislativo al "pueblo", un vistazo a las atribuciones de la Asamblea Nacional de Representantes de Corregimientos demuestra que las facultades legislativas de la nueva corporación eran bastante restringidas. Entre 1972 y 1984 , cuando dicha Asamblea estuvo vigente, los representantes se reunían anualmente durante un mes. Estas eran sus atribuciones:

1. Elegir al Presidente y Vicepresidente de la República una vez cada seis años ${ }^{12}$;

2. Aprobar o rechazar los tratados internacionales negociados por el Ejecutivo ${ }^{13}$;

3. Declarar la guerra o establecer la paz;

4. Aprobar o rechazar reformas a la división política de la República;

11 Columna suministrada por Brittmarie Janson Pérez. Francisco Linares fue Diputado por la Provincia de Panamá a las Asambleas de 1940-1944, 1952-1956 y 1964-1968. En cada uno de estos períodos se presentó como candidato del partido que en el momento de la elección dirigía su cuñado, Arnulfo Arias Madrid: El Partido Nacional Revolucionario (PNR, 1940-1944) y el Partido Panameñista (PP, 1952-1956 y 1964-1968).

12 La Asamblea de Representantes de Corregimientos nunca ejerció esta facultad con autonomía. En las dos ocasiones en que se reunió para elegir al Presidente y Vicepresidente de la República, se limitó a endosar la selección hecha anteriormente por el jefe militar, Omar Torrijos. Esta selección recayó en Demetrio Lakas en 1972 y Aristides Royo en 1978 (Koster y Sánchez, 1990: 215-16, 223; El Matutino, 2 de septiembre de 1978, texto obtenido a través de Brittmarie Janson Pérez).

13 Irónicamente, en la única ocasión en que la Asamblea de Representantes de Corregimientos intentó rechazar un tratado firmado por el Ejecutivo, la Guardia Nacional invadió la cámara y obligó a sus miembros a aprobar el convenio. Esto ocurrió en noviembre de 1980, mientras la Asamblea debatía el llamado "Tratado de Montería", que exime a los buques de guerra colombianos del pago de peajes por el uso del Canal de Panamá (Azcárate, 2000; La Prensa, 13 de noviembre de 1980, 13 de mayo de 1981). 
5. Conceder amnistía a prisioneros políticos; y

6. Redactar su reglamento interno.

La verdadera función legislativa, sin embargo, radicaba en un Consejo de Legislación, designado por el Ejecutivo, del cual formaba parte el jefe del régimen militar, Omar Torrijos, de acuerdo con el artículo 277 de la constitución de 1972 (Fábrega y Boyd Galindo, 1981: 7-97; Labrut, 1982: 154; Priestley, 1986: 76)14.

Si el régimen militar no concedió mayores poderes nacionales a los representantes de corregimientos, sí les otorgó, sin embargo, mayores atribuciones -y presupuestos- a nivel provincial, municipal y local (Fábrega y Boyd Galindo, 1981: 39-44, 71, 73-77; Labrut, 1982: 154; Priestley, 1986: 76). El régimen militar puso a disposición de los miembros de la Asamblea abundantes recursos para el financiamiento de "proyectos comunitarios" en corregimientos, distritos y provincias, lo que inauguró una tradición de acuerdo con la cual los representantes asumieron la construcción de calles, la compra de equipos deportivos, la distribución de regalos navideños, la asignación de becas y el pago de honras fúnebres de miembros de sus circunscripciones, todo con cargo al erario (Cochez, 1996).

En resumidas cuentas, las facultades legislativas concedidas a la Asamblea Nacional de Representantes de Corregimientos por la constitución de 1972 eran casi nulas, lo que contrasta significativamente con las disposiciones del régimen constitucional de 1946. La influencia ejercida por los miembros de la Asamblea de Representantes de Corregimientos tenía su raíz en las asignaciones presupuestarias otorgadas por el Ejecutivo para la realización de obras en sus pequeñas comunidades, lo que fortaleció significativamente los vínculos clientelistas entre los representantes y sus electores.

La estrategia de reducir el tamaño de las unidades electorales y menoscabar las facultades del órgano legislativo tuvo efectos negativos sobre el desarrollo democrático de Panamá. Entre 1972 y 1984, no existió en el país una asamblea representativa capaz de ejercer funciones democráticas elementales, como legislar o fiscalizar el funcionamiento de otros entes del Estado. La baja capacidad intelectual de la mayoría de los representantes restringió el potencial de la cámara para llevar a cabo otras funciones representativas básicas, como la deliberación, la socialización política, el reclutamiento de personal idóneo para el ejercicio de cargos administrativos o jurisdiccionales, la divulgación de información al público y el fortalecimiento de la nacionalidad. Éstas fueron las consecuencias de la aplicación de un arreglo electoral fundamentado en la proliferación de circuitos uninominales pequeños, pobres y rurales. Como resultado de las características estruc-

14 El artículo 277 reconoció "como Líder Máximo de la Revolución panameña al General de Brigada Omar Torrijos Herrera, Comandante Jefe de la Guardia Nacional. En consecuencia, y para asegurar el cumplimiento de los objetivos del proceso revolucionario, se le otorga, por el término de seis años, el ejercicio de las siguientes atribuciones: Coordinar toda la labor de la Administración Pública, nombrar y separar libremente a los Ministros de Estado y a los Miembros de la Comisión de Legislación; nombrar al Contralor General y a Subcontralor General de la República, a los Directores Generales de las entidades autónomas y semiautónomas y al Magistrado del Tribunal Electoral que le corresponde nombrar al Ejecutivo (...); nombrar a los Jefe y Oficiales de la Fuerza Pública (...); nombrar con la aprobación del Consejo de Gabinete a los Magistrados de la Corte Suprema de Justicia, al Procurador General de la Nación, al Procurador de la Administración y a sus respectivos suplentes; acordar la celebración de contratos, negociación de empréstitos y dirigir las relaciones exteriores. El General Omar Torrijos Herrera tendrá, además, facultades para asistir con voz y voto a las reuniones del Consejo de Gabinete y del Consejo Nacional de Legislación, y participar con derecho a voz en los debates de la Asamblea Nacional de Representantes de Corregimientos y de los Consejos Provinciales de Coordinación y de las Juntas Comunales (Fábrega y Boyd Galindo, 1981: 96-97). 
turales de estos nuevos círculos electorales -la mayoría situados en áreas rurales marginadas- la Asamblea poseía, en general, un nivel educativo bastante bajo (Janson Pérez, 2000).

Aparte de impedir el ejercicio de la representación democrática, la Asamblea de Representantes de Corregimientos promovió el clientelismo como medio de control social. El esquema operaba a dos niveles. En los corregimientos, el representante servía como agente del régimen militar en la distribución particularista de bienes públicos, ideada para adquirir apoyo para la dictadura. A nivel nacional, el funcionamiento de la Asamblea de Representantes de Corregimientos daba un barniz de legitimidad a un régimen interesado en propalar una imagen de "dictadura con cariño".

Los representantes aprobaban decisiones hechas por el Ejecutivo, frecuentemente a cambio de beneficios personales. En 1978, por ejemplo, Aristides Royo, candidato del régimen militar para Presidente de la República, se aseguró el apoyo de la mayoría de la Asamblea de Representantes de Corregimientos con promesas de asistencia médica vitalicia, subsidios por incapacidad, pensiones y funerales pagados para los 505 representantes. Para aumentar las opciones a su favor, Royo prometió a los 374 miembros que no lograron su reelección -pero a los que de todas maneras correspondía participar en la elección del Presidente de la República- que su gobierno continuaría pagándoles los salarios hasta que consiguieran otro empleo en el sector público (Crítica, 7 de octubre de 1978, obtenido a través de Brittmarie Janson Pérez).

En lo que atañe a la Asamblea, el legado más duradero del régimen militar fue un diseño electoral fundamentado en distritos pequeños y la reducción de las facultades de la cámara representativa. En el contexto panameño, ambos condujeron a la acentuación del clientelismo político. La imagen del representante como distribuidor de bienes públicos a cambio de apoyo político ya estaba, pues, firmemente arraigada cuando la dictadura castrense puso en funcionamiento un proceso de reforma política entre 1978 y 1983 . Tras la aprobación de una enmienda constitucional mediante referéndum, en 1983, la Asamblea de Representantes de Corregimientos y el Consejo de Legislación fueron reemplazados por la Asamblea Legislativa. Introducida durante el régimen militar, la nueva cámara funge todavía como el órgano legislativo panameño ${ }^{15}$.

A partir de 1983, el tamaño de los circuitos electorales (en términos proporcionales a la población total del país, según se explicó anteriormente) aumentó con respecto al sistema electoral de 1972, pues la reforma constitucional de 1983 estipuló el diseño de unidades electorales sobre la base de los distritos municipales, un peldaño arriba de los corregimientos en términos administrativos y de población. El tamaño de los circuitos electorales actualmente vigentes es, sin embargo, menor que el de las circunscripciones provinciales en vigor hasta 1968.

En distritos de poca población, las probabilidades de que un candidato sea conocido en persona por una proporción significativa del electorado es mayor que en circuitos con mayor número de votantes. Es en esos casos cuando una estrategia electoral basada principalmente en conexiones personales e inquietudes locales resulta viable. Este estilo de campaña electoral es más frecuente en áreas rurales y tradicionales, donde predominan el localismo y el personalismo. A medida que crece la población de los circuitos electorales, la proporción de los votantes conocida personalmente por los candidatos se reduce. Por lo tanto, para aumentar las posibilidades de triunfo 
electoral se hace necesario emplear estrategias de campaña basadas en asuntos ya no tanto personales y locales, sino regionales o nacionales (Katz, 1980: 30).

En virtud del legado histórico y las características estructurales de Panamá, un sistema electoral que estipula la elección de miembros de la asamblea representativa en circuitos de poca población tiende a reforzar la tradición clientelista. Manipular a los electores de circuitos de poca población para que decidan su voto, no sobre bases ideológicas o programáticas, sino por motivaciones clientelistas, les permite a los representantes de dichos circuitos perseguir sus propios intereses o la agenda de sus patrones políticos. Pueden así desvincularse de sus electores excepto en lo que atañe al continuo suministro de beneficios clientelistas, pues son conscientes de que serán juzgados en las urnas, no en base a su adhesión a principios o programas, sino a su habilidad para procurar y asignar bienes públicos de acuerdo con criterios particularistas.

Consecuentemente, en Panamá, el tamaño reducido de los circuitos electorales contribuye a perpetuar el clientelismo y menoscabar la representación democrática, una ficción jurídica de carácter público, que requiere rendición de cuentas y receptividad a los intereses del electorado. Este ensayo examina dicha hipótesis a partir de una comparación entre la calidad de los legisladores elegidos en 1999, en unidades submunicipales, de acuerdo con las disposiciones electorales de 1983 y los diputados a la Asamblea Nacional Constituyente elegidos en 1945, de acuerdo con un estatuto especial que dispuso su elección en circuitos provinciales y una gran circunscripción nacional.

\section{EL PREDOMINIO DE LAS CIRCUNSCRIPCIONES PEQUEÑAS}

En la actualidad, la fórmula electoral empleada para elegir a los legisladores panameños está estipulada en el Artículo 141 de la constitución política vigente, adoptada por el régimen militar en 1972 y reformada, en lo concerniente al sistema de elecciones, bajo el mismo régimen, en 1978 y $1983^{16}$. Esta fórmula dispone que la Asamblea Legislativa estará compuesta de los Legisladores que resulten elegidos en cada Circuito Electoral, de conformidad con las bases siguientes:

1. Cada Provincia y la Comarca de San Blas se dividirán en Circuitos Electorales.

2. La Provincia de Darién y la Comarca de San Blas tendrán dos Circuitos Electorales cada una, y en éstos se elegirá un Legislador por cada Circuito Electoral.

3. Los actuales Distritos Administrativos [municipales] que, según el último Censo Nacional de Población, excedan de cuarenta mil habitantes, formarán un Circuito Electoral cada uno y en tales circuitos se elegirá un Legislador por cada treinta mil habitantes y uno más por residuo que no baje de diez mil. El Distrito de Panamá se dividirá a su vez en cuatro Circuitos Electorales, de conformidad con el numeral cinco de este Artículo y según lo disponga la Ley. En los

16 La constitución de 1972 ha sido reformada en 1978, 1983, 1994 y 2004. Las reformas de 1978 y 1983 modificaron el régimen electoral. En lo concerniente a la cámara representativa, la reforma de 2004 estableció en 71 el número de sus integrantes, redujo la inmunidad de los miembros y estableció como requisito electoral el "no haber sido condenado por delito doloso con pena privativa de la libertad de cinco años o más". También cambió el nombre de la cámara a "Asamblea Nacional" y el de sus integrantes a "diputados", designación que tuvieron hasta el golpe militar de 1968. Ver el texto de la reforma en el sitio electrónico de la Asamblea, www.asamblea.gob.pa. La numeración del artículo concerniente a la elección de diputados cambió como consecuencia de esta reforma, pero momento de esta redacción, el texto único de la constitución reformada no ha sido emitido todavía. Por consiguiente, el artículo en cuestión seguirá siendo identificado, en lo que resta del texto, como el "Artículo 141". 
Circuitos Electorales en que se debe elegir a dos o más Legisladores, la elección se hará conforme al sistema de representación proporcional que establezca la Ley.

4. Excepto la Provincia de Darién, la Comarca de San Blas y los Distritos Administrativos actuales a que se refiere el numeral tres, anterior en cada Provincia habrá tantos Circuitos Electorales cuantos correspondan a razón de uno por cada treinta mil habitantes y uno más por residuo que no baje de diez mil, según el último Censo Nacional de Población, previa deducción de la población que corresponde a los actuales Distritos Administrativos de que trata el numeral tres. En cada uno de dichos Circuitos Electorales se elegirá un Legislador.

5. Cada Circuito Electoral tendrá un máximo de cuarenta mil habitantes y un mínimo de veinte mil habitantes, pero la Ley podrá crear Circuitos Electorales que excedan el máximo o reduzcan el mínimo anteriores, para tomar en cuenta las divisiones políticas actuales, la proximidad territorial, la concentración de la población indígena, los lazos de vecindad, las vías de comunicación y los factores históricos y culturales, como criterios básicos para el agrupamiento de la población en Circuitos Electorales (Bernal, 1995: 51-52).

Aparte de lo complicado del procedimiento, de la lectura de su texto queda claro que éste fue expresamente diseñado para favorecer a circunscripciones electorales de baja población y, según lo arguye este estudio, de fácil manipulación. En 1999, la base electoral de 20, 30 y 40 mil habitantes dispuesta en el Artículo 141 representaba entre el $0.07 \%$ y el $0.14 \%$ de la población total de Panamá, estimada en 2.8 millones de habitantes. En contraste, en 1945, bajo el régimen electoral adoptado para la elección de diputados a la Convención Nacional Constituyente, el número de habitantes de la menos poblada de las circunscripciones electorales (la Provincia del Darién) representaba el $2.4 \%$ de la población total de la República, estimada en 700,000 habitantes. En ese año, como ya ha sido señalado, el territorio nacional se dividió en nueve circuitos electorales, correspondientes a las provincias del país, a los que se añadió una circunscripción nacional. Como ha sido definido aquí (en términos de la proporción total de la población residente en las unidades electorales), el tamaño de los circuitos era mayor en 1945 que en 1999.

Aplicando el método comparado, este estudio examina la hipótesis que sostiene que un sistema electoral basado en distritos electorales de reducida población, en un contexto político caracterizado por el particularismo, el bajo contenido programático y la desigualdad tiende a la elección de personal poco idóneo para el adecuado ejercicio de la función representativa, fundamental en todo Estado democrático. La comparación de las Asambleas panameñas elegidas en 1945 y 1999 da crédito a este planteamiento. Los diputados de la Asamblea Nacional Constituyente de 1945, elegidos en distritos electorales más grandes que aquellos de 1999, poseían una educación más amplia y credenciales más sólidas de las que tenían los legisladores elegidos en 1999. La mayoría de los actuales miembros de la Asamblea Legislativa son "políticos de carrera", que iniciaron su vida profesional como funcionarios gubernamentales durante la dictadura castrense 0 son producto de un sistema educativo cuyos niveles han descendido notoriamente en las últimas décadas, debido a las drásticas reformas llevadas a cabo después del golpe de Estado de octubre de 1968, con el propósito de asegurar la lealtad de estudiantes y profesores universitarios al régimen militar (Koster, 2000; Pereira, 1979: 123-24, 136; El Panamá América, 17 de diciembre de 2000). Tal como lo confirma el registro histórico (Sánchez Borbón, 1993), el diseño electoral explica parcialmente por qué los miembros de la Asamblea de 1945 fueron mejores representantes que aquellos elegidos bajo la constitución de 1972, reformada en 1983. 


\section{IDONEIDAD Y REPRESENTACIÓN}

Las teorías sobre los efectos de los sistemas electorales señalan que el interés de los partidos por presentar candidatos con un nivel educativo superior, que posean la capacidad de atraer a un segmento más amplio de la sociedad, se reduce a medida que disminuye la población del circuito electoral. En las circunscripciones de mayor población, las posibilidades que tiene el partido para triunfar aumentan con la presentación de candidatos más conocidos por la población. A un nivel más amplio, en que los nexos locales son raras veces suficientes para garantizar el triunfo electoral (Katz, 1980: 30) y en el que debe disminuir la proliferación de las malas prácticas censuradas por Madison, la elección de candidatos tiene mayores posibilidades de lograrse con base en orientaciones políticas que en los distritos más pequeños, donde la manipulación resulta más fácil y los vínculos clientelistas son suficientes para garantizar la elección.

El sentido común indica que aquellos individuos con una reputación más vasta, fundamentada en la aplicación de un programa político con cierta coherencia ideológica, tienen mayores posibilidades de convertirse en auténticos representantes democráticos que aquellos cuyo atractivo descansa meramente en ejecutorias de tipo clientelista. Asegurar que el sistema electoral incentive el ejercicio de cargos públicos por individuos idóneos es un objetivo común a todos los sistemas democráticos, en virtud de las complejas situaciones que enfrentan los Estados modernos. Sin duda, los individuos de reconocida competencia tienen mayores posibilidades de llevar a cabo las espinosas tareas de la representación democrática, tal como la define Pitkin (1967) -un ejercicio sustantivo en favor de terceros, que requiere acción independiente en el interés del electorado así como responsabilidad hacia éste- que sus pares menos calificados. Si aplicamos el argumento de Madison a un país como Panamá -con una población pequeña, poco contenido ideológico en la política, una mala distribución de los recursos y su extrema concentración en las áreas urbanas-, la baja población de las circunscripciones electorales y una representación desproporcionada de las áreas rurales marginadas, tal como lo estipula el Artículo 141 de la constitución de 1972, disminuyen las probabilidades de asegurar la elección de una Asamblea integrada por individuos capaces.

Quienes se han dedicado al análisis de la Asamblea Legislativa han identificado en este aspecto una de las razones de lo que en forma consistente han catalogado como la incapacidad de la mayoría de los miembros de la cámara (Galindo Heurtematte, 1999; Ricord, 1999). En términos de capacidad intelectual, no cabe duda de que la Asamblea Nacional-elegida entre 1904 y 1968 en circuitos provinciales- tuvo mayor éxito que la Asamblea Legislativa en la tarea de reclutar individuos de agudeza intelectual. Un examen de la lista de los miembros de la Asamblea desde 1904 hasta 1968 revela que muchos de los principales intelectuales y políticos de Panamá también ejercieron como diputados en algún momento de sus trayectorias ${ }^{17}$.

17 Entre ellos, Guillermo Andreve, Francisco Arias Paredes, Harmodio Arias Madrid, Aristides Arjona, Maximiliano Arosemena, Pablo Arosemena, Abel Bravo, Eduardo Chiari, Roberto F. Chiari, Héctor Conte Bermúdez, José Daniel Crespo, Arnulfo EscaIona Ríos, José Isaac Fábrega, Julio J. Fábrega, Octavio Fábrega, Sergio González Ruiz, Aurelio Guardia Ponce, Víctor Florencio Goytía, Enrique A. Jiménez, Thelma King, Samuel Lewis Arango, Guillermo Méndez Pereira, Eusebio A. Morales, Víctor Navas, Esther Neira, Mario J. de Obaldía, Gumersinda Páez, José Pezet, Demetrio Porras, Aníbal Ríos, Diógenes de La Rosa, Acracia Sarasqueta, Juan B. Sosa, Sebastián Sucre, Carlos Sucre Calvo, Gil Blas Tejeira, Domingo H. Turner, Nicolás Victoria Jaén, y Carlos Iván Zúñiga. Las "malas prácticas" propias de política electoral de Panamá, no obstante, también impidieron que otras figuras prestantes ejerciesen funciones representativas. Los casos de José de la Cruz Herrera y Gregorio Miró, dos de los principales intelectuales conservadores de Panamá, ilustran este aspecto nefasto de la política panameña. En la década de 1920, la manipulación electoral impidió que ambos accediesen a una diputación (Miró, 1995: 134). 
Muchos de éstos eventualmente fungieron como ministros de Estado, embajadores, magistrados de la Corte Suprema y presidentes de la República. De los 26 presidentes que tuvo Panamá entre 1904 y 1968, nueve ejercieron como diputados a la Asamblea Nacional antes de ascender al solio presidencial. Por lo menos cuatro de ellos -Manuel Amador Guerrero, José Domingo de Obaldía, Carlos A. Mendoza y Belisario Porras- se desempeñaron como miembros de asambleas locales 0 nacionales durante el período de unión a Colombia (1821-1903). En total, al menos la mitad de los presidentes de Panamá entre 1904 y 1968 adquirieron experiencia política previa en la Asamblea Nacional. En contraste, ninguno de los presidentes elegidos con posterioridad al desalojo de la dictadura militar ha sido miembro de la cámara legislativa antes de su elección presidencial. La Tabla 1 resume estos hallazgos: 
TABLA 1: Desempeño previo de los presidentes panameños como diputados 1904-1968; 1989-1999

Presidente

1. Manuel Amador Guerrero

2. José Domingo de Obaldía

3. Carlos A. Mendoza

4. Pablo Arosemena

5. Belisario Porras

6. Ramón Maximiliano Valdés

7. Ciro Luis Urriola

8. Ernesto T. Lefevre

9. Rodolfo Chiari

10. Florencio H. Arosemena

11. Ricardo J. Alfaro

12. Harmodio Arias Madrid

13. Juan Demóstenes Arosemena

14. Augusto Samuel Boyd

15. Arnulfo Arias Madrid

16. Ricardo Adolfo de La Guardia

17. Enrique A. Jiménez

18. Domingo Díaz Arosemena

19. Daniel Chanis

20. Alcibíades Arosemena

21. José Antonio Remón

22. José Ramón Guizado

23. Ricardo Arias Espinosa

24. Ernesto de La Guardia

25. Roberto F. Chiari

26. Marco A. Robles

27. Guillermo Endara Galimany

28. Ernesto Pérez Balladares

29. Mireya Moscoso

30. Martín Torrijos
Período presidencial

1904-1908

1908-1910

1910

1910-1912

1912-1916; 1918-1920; 1920-1924

1916-1918

1918

1920

1924-1928

1928-1931

1931-1932

1932-1936

1936-1939

1939-1940

1940-1941; 1949-1951; 1968

1941-1945

1945-1948

1918-1928

1948-1949

1949

1951-1952

1952-1955

1955

1955-1956

1956-1960

1960-1964

1940-1944

1964-1968

1948-1952 durante: 1906-1910 diputación)

1904-1906

1924-1928

1914-1918

1932-1936
Ejerció como representante

Régimen colombiano

Régimen colombiano

Régimen colombiano

Régimen colombiano;

Régimen colombiano; 1918 (no ejerció la

1904-1906; 1910-1918

1989-1994

1994-1999

1999-2004

2004 


\section{LA POLITICA COMO VOCACIÓN Y LOS PERFILES DE LOS REPRESENTANTES}

Un diseño electoral basado en distritos de mayor población y el ejercicio de funciones constitucionales más amplias permitió a la Asamblea Nacional asumir las tareas de reclutamiento y entrenamiento de dirigentes políticos en forma más eficiente que la Asamblea Legislativa. El reclutamiento y entrenamiento políticos son funciones de la asamblea representativa a las que Max Weber (1978 [1918]) asigna particular importancia ${ }^{18}$. En su célebre monografía sobre las posibilidades para la consolidación democrática en la Alemania de la posguerra, Weber sostiene que en el Estado moderno, la preservación y promoción de la libertad individual requieren el ejercicio del gobierno por políticos talentosos, responsables de sus actos ante la asamblea representativa, en oposición a una administración pública por burócratas y tecnócratas ciegamente obedientes a quien ostenta el poder ejecutivo.

Weber es partidario de un diseño electoral que logre incorporar a individuos aptos a la asamblea representativa, donde a través del desempeño de las funciones legislativas, deliberativas y fiscalizadoras, recibirían adiestramiento para el ejercicio adecuado y responsable de la toma de decisiones y la supervisión democrática. De esta forma, la experiencia política adquirida prepararía a los políticos más competentes de la cámara para asumir posiciones de liderazgo en la administración pública.

Una comparación entre los perfiles profesionales de los diputados de 1945 y los legisladores de 1999 proporciona evidencia que sustenta la tesis de que las circunscripciones de menos habitantes tienen mayores posibilidades de elegir representantes de experiencias limitadas y visión restringida que los circuitos de mayor población. En adición a las teorías de Madison y Katz, en su ensayo La política como vocación (1919), Weber ofrece una guía de gran utilidad para el ejercicio aquí propuesto. En su ensayo, Weber distingue a los políticos que viven para la política de los que viven de ella. "Aquel que intenta hacer de la política una forma permanente de fuente de ingresos vive de la política como una vocación, mientras que aquel que no lo hace, vive para la política".

El político que vive "para" la política no utiliza sus habilidades y pensamiento en forma exclusiva 0 , al menos, en forma primordial para recibir remuneración económica. En otras palabras, ejercer una función pública para obtener un ingreso no es su preocupación principal, ya sea porque la acumulación de riquezas personales no constituye una motivación demasiado importante o porque posee una renta independiente que le proporciona un modus vivendi aceptable. De acuerdo con Weber, este tipo de político, para el cual las ganancias económicas no son la principal preocupación, posee mejores atributos para dedicarse al bienestar de la res publica. Por el contrario, aquel que se empeña en hacer de la política una fuente permanente de ingresos vive "de" la política. Este tipo de político se preocupa en primer lugar -y por encima de todo- de lograr un sustento proveniente de la actividad política:

El político profesional que vive "de" la política puede ser un puro "prebendado" o un "funcionario" a sueldo. 0 recibe ingresos provenientes de tasas y derechos por servicios determinados (las propinas y cohechos no son más que una variante irregular y formalmente ilegal de este tipo de ingresos), o percibe un emolumento fijo en especie 0 en dinero, 0 en ambas cosas a la vez. Puede asumir el carácter de un 'empresario', como sucedía con el condottiero o el arrendatario o comprador de un cargo en el pasado y sucede hoy con el boss americano, que

18 Agradezco esta referencia a Guillermo O'Donnell, de la Univrsidad de Notre Dame. 
considera sus gastos como una inversión de capital a la que hará producir beneficios utilizando sus influencias. 0 recibe un sueldo fijo, como es el caso del redactor de un periódico político, o de un secretario de partido o de un ministro o funcionario político moderno (...) Lo que los jefes de partido dan hoy como pago de servicios leales son cargos de todo género en partidos, periódicos, sociedades cooperativas, cajas del seguro social y organismos municipales o estatales (Weber, 1919).

Las categorias de Weber son tipos puros, versiones ideales de la realidad política con fundamento en una experiencia histórica distinta a la nuestra, creadas para satisfacer propósitos analíticos. En la actualidad, es difícil vivir "para" la política (o cualquier otra actividad pública) si la actividad no tiene un valor de mercado suficiente que permita al individuo dedicarse a ella a tiempo completo. Pero si afinamos el argumento de Weber, es posible llegar a una distinción pertinente a nuestros propósitos analíticos. La política como vocación y la política como "saqueo" constituyen dos modos de actividad opuestos -el primero guiado por una ética profesional y el segundo, por una cosmovisión patrimonialista ${ }^{19}$. Más probabilidades de ser buen representante tiene quien participa en la política por vocación que quien practica la política como "saqueo".

Un estudio de los antecedentes de los representantes revela que el típico diputado a la Asamblea Nacional en 1945 -elegido en una circunscripción electoral nacional o provincial- se aproximaba a la categoría weberiana del individuo para el cual la política es vocación. De los 51 integrantes de la Convención Nacional Constituyente de 1945, 43 fueron elegidos por las provincias y nueve por un único circuito nacional.

En aquel año, el diputado típico era un hombre de 45 años, dedicado principalmente a negocios particulares, ya fuera como comerciante, empresario, agricultor, industrial o administrador. También tenía experiencia previa -esto es, anterior a la ocupación que ejercía en el momento de la eleccióncomo servidor público o profesional liberal. Si bien la gestión pública no era una actividad principal para la mayoría -solamente el 18\% informó que su ocupación principal en el instante de la elección era el ejercicio de un cargo público- una mayoría considerable de diputados (61\%) había servido previamente en el gobierno, ya fuere como funcionario designado o elegido. Además, un grupo substancial (también el 61\%) había ejercido una profesión liberal, en especial el derecho, la educación, la medicina, el periodismo, o la ingeniería. Típicamente, la mayoría se había dedicado a más de dos actividades profesionales durante su carrera (2.4 es el promedio estadístico).

Poco menos de un tercio de la Asamblea Nacional (el 31\%) tenía experiencia previa en el ramo educativo. Las dos diputadas que señalaron al magisterio como su actividad principal -Esther Neira y Gumersinda Páez- tuvieron trayectorias distinguidas en ese campo. Aproximadamente una cuarta parte de la cámara (el 24\%) había estudiado en el extranjero, en universidades angloamericanas de prestigio: tres en Georgetown, dos en Columbia, uno en Tulane, y otro en Cambridge, Inglaterra. Uno de los egresados de Georgetown, Harmodio Arosemena Forte, hijo del ex diputado y Presidente de la República Pablo Arosemena, sobresalió como abogado y orador. "Escritor" fue la profesión declarada por tres de los 51 diputados a la Asamblea. Dos de éstos, Diógenes de La Rosa y Gil Blas Tejeira, se cuentan entre los más reputados ensayistas y comentaristas políticos de Panamá. Al menos dos eran miembros de prestigiosas sociedades intelectuales: los diputados 
de La Rosa (Academia Panameña de la Historia) y José Isaac Fábrega, otro prominente abogado (Academia Panameña de la Lengua) (Moscoso, Cabezas, y Aguilera, 1945).

Por el contrario, en 1999 el legislador típico -elegido a nivel municipal o submunicipal, según el Artículo 141 de la constitución arriba citado- se aproximaba al tipo que, según Weber, vive "de" la política. En ese año, el miembro promedio de la Asamblea era un político profesional, un hombre de 47 años. El ejercicio de un cargo público era la principal actividad de la mayoría (61\%) en el momento de su elección (o reelección). Ésta, sin lugar a dudas, es una consecuencia del abultamiento del sector público durante los años del régimen militar (1968-1989), una característica que va de la mano de un significativo deterioro de la calidad de los servicios públicos (Koster y Sánchez, 1990: 138, 248; Priestley, 1986: 110, 129). Sin embargo, era escasa la experiencia previa en el sector público (12 por ciento), lo que indica mayor "especialización" profesional y antecedentes profesionales más restringidos.

Sólo el $12 \%$ declaró que los negocios particulares eran su principal actividad y un $24 \%$ se identificó como practicante de una profesión liberal. Sólo el 25\% afirmó poseer experiencia previa en el ámbito de los negocios. Una porción más pequeña (el 43\%) informó poseer experiencia previa en el ejercicio de alguna de las humanidades, en comparación con el 61\% que en 1945 poseía esta experiencia. Por lo demás, la Asamblea de 1999 no contaba entre sus miembros con ningún escritor o miembro de sociedades intelectuales. En su mayoría, los integrantes de la Asamblea elegida en 1999 eran producto del sistema educativo público y, en especial, de la Universidad de Panamá, cuya calidad ha descendido progresivamente desde el golpe militar de 1968 (Koster, 2000). El legislador prototípico de 1999 se ha dedicado a dos actividades profesionales durante su carrera, un promedio estadístico un tanto inferior al 2.4 del diputado arquetípico en 1945.

Poco menos de una quinta parte de la Asamblea Legislativa (el 18\%) declaró tener experiencia previa como profesor o maestro, muy por debajo del $31 \%$ de 1945. Un tercio de la Asamblea de 1999, en comparación con el 24\% en 1945, llevó a cabo estudios universitarios en el extranjero. Este tercio ha estudiado principalmente en universidades iberoamericanas, como el Instituto Centroamericano de Estudios Avanzados (INCAE) de San José, Costa Rica y la Universidad Nacional Autónoma de México (UNAM), las más mencionadas. La Tabla 2 resume estos resultados y proporciona estadísticas sobre los antecedentes de los miembros de las Asambleas de 1945 y de 1999 y, para esta última cámara, distingue entre los legisladores elegidos en distritos "uninominales" y los "plurinominales". En general, los antecedentes de los legisladores elegidos en los circuitos "uninominales" son más restringidos que los de los legisladores elegidos en los "plurinominales", como puede verse claramente a continuación: 
TABLA 2: Comparación de los perfiles profesionales de los miembros de la Asamblea de Panamá, 1945, 1999

\begin{tabular}{|c|c|c|c|c|}
\hline & 1945 & & 1999 & \\
\hline & $\begin{array}{l}\text { Todos los } \\
\text { circuitos }\end{array}$ & $\begin{array}{l}\text { Todos los } \\
\text { circuitos }\end{array}$ & $\begin{array}{l}\text { Circuitos } \\
\text { uni- } \\
\text { nominales }\end{array}$ & $\begin{array}{l}\text { Circuitos } \\
\text { pluri- } \\
\text { nominales }\end{array}$ \\
\hline Edad promedio al asumir el cargo & 45 & 47 & 45 & 48 \\
\hline Número promedio de actividades profesionales declaradas & 2.4 & 2.0 & 1.9 & 2.0 \\
\hline Principal actividad: sector público & $18 \%$ & $61 \%$ & $64 \%$ & $60 \%$ \\
\hline Principal actividad: negocios particulares $\left({ }^{*}\right)$ & $51 \%$ & $12 \%$ & $8 \%$ & $14 \%$ \\
\hline Principal actividad: profesión liberal 0 actividad gremial $\left({ }^{* *}\right)$ & $31 \%$ & $24 \%$ & $28 \%$ & $21 \%$ \\
\hline Experiencia previa en el sector público & $61 \%$ & $12 \%$ & $20 \%$ & $7 \%$ \\
\hline Experiencia previa en negocios particulares & $12 \%$ & $25 \%$ & $28 \%$ & $24 \%$ \\
\hline Experiencia previa en una profesión liberal & $61 \%$ & $43 \%$ & $36 \%$ & $48 \%$ \\
\hline Principal actividad: escritor & $6 \%$ & $0 \%$ & $0 \%$ & $0 \%$ \\
\hline Principal actividad: educador & $4 \%$ & $3 \%$ & $8 \%$ & $0 \%$ \\
\hline Experiencia previa como educador & $31 \%$ & $18 \%$ & $12 \%$ & $21 \%$ \\
\hline Participación en sociedades intelectuales & $6 \%$ & $0 \%$ & $0 \%$ & $0 \%$ \\
\hline Estudios universitarios en el extranjero & $24 \%$ & $33 \%$ & $36 \%$ & $31 \%$ \\
\hline Estudios en universidades angloamericanas & $24 \%$ & $13 \%$ & $16 \%$ & $12 \%$ \\
\hline Estudios en universidades iberoamericanas & $0 \%$ & $19 \%$ & $20 \%$ & $19 \%$ \\
\hline Número promedio de representantes por circuito $\left({ }^{* * *}\right)$ & 6.8 & 1.8 & 1 & 3.2 \\
\hline Número de casos $\left({ }^{* * * *}\right)$ & 51 & 67 & 25 & 42 \\
\hline
\end{tabular}

Fuentes: Moscoso, Cabezas y Aguilera, 1945; los expedientes de los legisladores aparecen en el portal electrónico de la Asamblea Legislativa (http://www.asamblea.gob.pa/). Agradezco a Marcela Endara la consecución de los expedientes de los legisladores.

* Contadores, ejecutivos de empresa, administradores, propietarios, agricultores, industriales, terratenientes, comerciantes.

** Abogados, dirigentes cívicos y sindicales, educadores, ingenieros, médicos, escritores.

*** Como los circuitos de mayor población eligen mayor número de representantes, el número promedio de representantes por circuito sirve como indicador del tamaño de la circunscripción.

**** La Asamblea que se eligió en 1999 tenía 71 miembros, de los cuales 67 habían proporcionado información sobre sus antecedentes personales en el portal electrónico de la Asamblea en el momento de la redacción de este estudio. No había información sobre los legisladores Pedro Miguel González (PRD), José Muñoz (PA), Jacobo Salas (PA) y Gloria Young (PA).

En 1945, era probable que un diputado comenzase su carrera profesional como maestro de escuela ${ }^{20}$. Después de recibirse en un instituto de educación superior, pudo haberse dedicado al ejercicio de una profesión liberal, a negocios particulares y/o al desempeño de un cargo público. En este sentido, la trayectoria de Homero Ayala puede considerarse prototípica. Después de obtener su diploma de maestro, trabajó inicialmente como educador, director de escuela e inspec-

20 Debido a que un diploma de maestro era uno de los pocos títulos profesionales que se podían obtener en Panamá a comienzos del siglo XX, muchos de los principales intelectuales y estadistas de la época iniciaron sus carreras como maestros de aula. En este contexto, el grado de maestro servía como instrumento de adelanto social. 
tor de instrucción pública. Fue dirigente magisterial, presidente de la Asociación de Maestros e integrante destacado del Partido Liberal. Miembro de Acción Comunal, participó en la insurrección del 2 de enero de 1931 y bajo la presidencia de Ricardo J. Alfaro (1931-1932), fue Comandante de la Policía Nacional. Su principal fuente de ingresos, sin embargo, era el comercio, actividad a la se dedicó durante gran parte de su vida y a la que regresó después del término de su diputación en 1948 (Moscoso, Cabezas y Aguilera, 1945: 184).

En 1999, era probable que un legislador hubiese comenzado su vida profesional como empleado público, como en el caso de Manuel de La Hoz (PRD, luego PA). Después de obtener una Licenciatura en Administración Pública en la Universidad de Panamá, consiguió un empleo en la Contraloría General de la República, donde trabajó durante la dictadura militar. Como resultado del desalojo de esa dictadura, en 1989, de La Hoz se desempeñó como gerente de un modesto establecimiento comercial y siguió participando en las actividades políticas del PRD en Río Abajo, un sector marginado de la ciudad de Panamá. Fue elegido legislador en 1994 y en 1999 obtuvo la reelección (República de Panamá, Asamblea Legislativa, www.asamblea.gob.pa).

\section{HUMANISMO, CLIENTELISMO Y REPRESENTACIÓN}

El ejercicio aquí expuesto indica que los constituyentes de 1945 poseían una formación humanista más amplia que los legisladores de 1999. Este rasgo, aunado al hecho de que los miembros de la Asamblea Nacional de 1945 se aproximaban más al tipo que vive "para" la política, les proporcionó mejores herramientas para cumplir con sus deberes representativos. De hecho, al describir las conductas asociadas a sus categorías, en el ensayo Parlamento y gobierno en una Alemania reconstruida, Weber señaló:

The professional politician may live merely from politics and its hustle and bustle, or he may live for politics. Only in the latter case can he become a politician of great calibre (1978 [1918] $)^{21}$.

La Asamblea de 1945, que inicialmente se reunió como Convención Constituyente, aprobó la Constitución de 1946, considerada ampliamente como la mejor de las constituciones panameñas. Además, aprobó leyes avanzadas en otros ramos, incluyendo un Código Laboral progresista y emprendió una exhaustiva revisión de las relaciones entre Panamá y Estados Unidos, que culminó en el rechazo del Convenio de Bases de 1947. Si bien estos logros no pueden ocultar sus fallas -su pretensión de reasumir las facultades constituyentes en 1948-, la Asamblea de 1945, sin lugar a dudas, ocupa una posición más ventajosa frente a las cámaras elegidas con posterioridad a 1983 en lo que respecta a representatividad, responsabilidad, sensibilidad y transparencia, sin mencionar la capacidad intelectual de los integrantes (Sánchez Borbón, 1993).

La comparación de las Asambleas de 1945 y 1999 ayuda a ilustrar el efecto del tamaño del circuito electoral sobre la capacidad de los representantes. La Asamblea de 1945 fue elegida sobre una base más amplia que cualquier otra Asamblea panameña, ya que la fórmula electoral que se empleó combinaba distritos electorales provinciales con una circunscripción nacional. En

${ }^{21} \quad$ "El político profesional puede vivir meramente de la política y su algarabía o puede vivir para la política. Sólo en el ultimo caso puede convertirse en un político de gran calibre" (traducción del autor). 
Panamá, la introducción de diputaciones nacionales fue propuesta inicialmente en 1924 por Guillermo Andreve, reputado intelectual y estadista, como una iniciativa para mejorar la calidad de la representación política. La aspiración de Andreve era "llevar a la Asamblea un núcleo de individuos preparados que pudieran encauzar a sus colegas por el camino del trabajo activo, honrado, patriótico y provechoso que el país espera siempre de las Asambleas" (Andreve, 1979 [1924]: 221).

Dos décadas más tarde, la fórmula de Andreve se puso en práctica para la elección de la Asamblea Nacional Constituyente de 1945. Tal cual lo comentó en su Alocución del 3 de febrero de 1945 el presidente Ricardo Adolfo de La Guardia, el doble sistema de candidatos provinciales y nacionales se estableció "a fin de que mediante los últimos haya la certeza de que concurrirán a prestar su concurso a la Constituyente ciudadanos de primera línea por su preparación y por la confianza que despiertan en la totalidad del país" (Moscoso, Cabezas y Aguilera, 1945: 25).

En consecuencia, para las nueve diputaciones nacionales, los partidos que se disputaban la elección hicieron un esfuerzo por presentar como candidatos a individuos que poseían un sólido prestigio en el ámbito nacional: hombres y mujeres que vivían "para" la política, tales como José Isaac Fábrega, Esther Neira, y Diógenes de La Rosa, entre otros (Sánchez Borbón, 1993). A un nivel inferior, en los distritos electorales provinciales, la mayoría de los candidatos triunfadores poseían reputaciones adecuadas en el medio provincial, no solamente en sus municipios o corregimientos.

Contrario sensu, en 1999 -como en 1994, 1989 y 1984- ser conocido en la esfera municipal o comunitaria como proveedor de servicios "clientelistas" bastaba para conseguir la elección o la reelección como legislador. Esta distinción, según se arguye aquí, obedece en gran medida al sistema electoral adoptado durante la dictadura militar, a través de la constitución de 1972 y sus enmiendas $(1978,1983)$. Mediante estas reformas, la dictadura pretendió dar un barniz seudo democrático al ordenamiento jurídico panameño, entre otras medidas a través de la reintroducción de una asamblea ostensiblemente representativa. Un diseño que promueve el clientelismo y la mediocridad, aunado a las restringidas facultades constitucionales que le concedió el texto fundamental, sin embargo, garantizarían su sujeción al ejecutivo, entonces controlado por los militares ${ }^{22}$.

En síntesis, en distritos electorales de mayor población, un candidato a diputado, para asegurar su elección, debe poseer una reputación más amplia que la que proveen únicamente los logros "clientelistas". Pero en aquellos lugares donde prevalecen el clientelismo, así como la mala distribución de los recursos y donde el contenido programático del debate político es débil, un sistema diseñado sobre la base de circuitos electorales de baja población propenderá a la elección de representantes de capacidad limitada y mentalidades restringidas. Los representantes elegidos en distritos pequeños y marginales, con antecedentes limitados basados en sus logros clientelistas, tienen menos posibilidades de ejercer adecuadamente la representación democrática que diputados escogidos en circunscripciones más grandes. Esto lo demuestra patentemente la comparación de las Asambleas elegidas en Panamá en 1945 y 1999. 


\section{CONCLUSIÓN}

Como en otros países de la región, en Panamá la representación política atraviesa actualmente por una grave crisis. Las acusaciones de cohecho y tráfico de influencias emitidas contra miembros de la Asamblea Legislativa en los últimos tiempos constituyen síntomas indiscutibles de esta crisis.

La representación política es un elemento fundamental del Estado moderno, sin el cual el sistema democrático no es factible en las sociedades contemporáneas, pues la magnitud de su población impide la práctica de la democracia directa a nivel del Estado-nación. La obra reveladora de Hannah Pitkin, The Concept of Representation (1967), define la representación como un ejercicio sustantivo en favor de terceros, que requiere acción independiente en el interés del electorado así como responsabilidad hacia éste.

A partir de esta definición, este estudio explica parcialmente el fenómeno -la crisis de representación- sobre la base de un aspecto esencial del sistema electoral panameño: el tamaño reducido de las circunscripciones electorales. El razonamiento se inspira en las tesis de James Madison (1987 [1787]) y Richard Katz (1980), entre otros, quienes atribuyen ciertos comportamientos de los representantes al diseño electoral de la unidad política (específicamente, al tamaño de las circunscripciones electorales). Las proposiciones de Madison y Katz se complementan con la tipología del comportamiento político elaborada por Max Weber (1978 [1918] y 1946 [1919]), que plantea la diferencia entre el individuo que vive "para" la política y el que vive "de" la política.

Las teorías señaladas guían una comparación de las calificaciones del personal de dos cámaras representativas panameñas: la Asamblea Nacional Constituyente de 1945 y la Asamblea Legislativa de 1999. Este ejercicio histórico se nutre del compendio biográfico de los diputados de 1945, publicado en ese año por Antonio Moscoso, Carlos Cabezas y Rodolfo Aguilera, Jr., así como de las biografías de los legisladores de 1999 contenidas en el sitio electrónico de la Asamblea Legislativa (www.asamblea.gob.pa). También se basa en opiniones de analistas de la política panameña, tales como Mario Galindo Heurtematte, Humberto E. Ricord y Guillermo Sánchez Borbón.

El ejercicio concluye que en 1945, la organización de los comicios con base en circuitos provinciales y una gran circunscripción nacional contribuyó a producir la elección de individuos mejor calificados para ejercer funciones representativas que en 1999, cuando los legisladores fueron escogidos en circuitos municipales o submunicipales, según lo dispone el Artículo 141 de la constitución de 1972. Los resultados concretos de una mejor calidad de representación democrática son evidentes en los frutos de la Asamblea de 1945, que promulgó el texto ampliamente considerado como la mejor de las constituciones panameñas, incorporó avanzadas disposiciones sociales al ordenamiento jurídico panameño y emprendió una exhaustiva revisión de las relaciones entre Panamá y Estados Unidos, que culminó en el rechazo del Convenio de Bases de 1947. Esta labor contrasta notoriamente con los frutos de la Asamblea elegida en 1999 y en ocasiones anteriores, bajo la constitución de 1972.

Un análisis más exhaustivo es necesario para sustentar la validez de este argumento. Podría argüirse, por ejemplo, que existe un deterioro de la clase política que precede a los efectos del sistema electoral. En otras palabras, es posible argumentar que el descenso de la calidad de los diputados obedece a factores sociohistóricos más que a variables institucionales. La pregunta que naturalmente genera este razonamiento es: ¿Cómo podría discriminarse entre los efectos del 
sistema electoral y los de otras variables históricas o sociológicas, en el afán de explicar el menoscabo de la idoneidad de los miembros de la asamblea representativa y, por ende, de la calidad de la representación política ejercida por ellos? ${ }^{23}$ Para abordar este punto con eficiencia, podrían contrastarse las biografías de diputados y legisladores con las de políticos y funcionarios públicos de alta jerarquía que no fueron o no son elegidos. Si resulta que la calidad de los funcionarios no elegidos en 1945 es superior a la de sus pares en 1999, factores sociohistóricos, por identificar, podrían ser más efectivos que el sistema electoral para explicar el fenómeno.

Sea como fuere, el ejercicio presentado aquí es útil como punto de partida para un debate razonado sobre la capacidad de las instituciones políticas para producir resultados democráticos, en general y, en particular, sobre los efectos del tamaño de los circuitos electorales en la calidad de la representación democrática. En un contexto de crecientes demandas ciudadanas de mayor transparencia y vocación de servicio en el ejercicio de cargos públicos, estas cuestiones cobran cada vez más pertinencia.

\section{REFERENCIAS}

Andreve, Guillermo. 1979 [1924]. "Cuestiones legislativas". Revista Lotería 282-283-284: 205-54.

Azcárate, Fermín. 2000. "Recordando a Julio E. Linares”. El Panamá América, 22 de abril.

Berguido Guizado, Fernando. 1987. La sucesión presidencial en Panamá. Panamá: Editorial La Antigua.

Bernal, Miguel Antonio. 1995. Constitución de la República de Panamá de 1972. Panamá: Instituto de Estudios Políticos e Internacionales (IEPI).

Biesanz, John y Mavis Hiltunen, Biesanz. 1955. The People of Panama. New York: Columbia University Press.

Crítica, Diario, Panamá.

Cochez, Guillermo A. 1996. "Las partidas circuitales de los legisladores". La Prensa, 23 de diciembre, pág. 46A.

Dahl, Robert A. 1989. Democracy and Its Critics. New Haven: Yale University Press.

El Matutino, Diario, Panamá.

El Panamá América, Diario, Panamá. Versión electrónica. (www.elpanamaamerica.com.pa).

Epstein, David F. 1984. The Political Theory of The Federalist. Chicago: University of Chicago Press.

Fábrega, Ramón y Mario Boyd Galindo. 1981. Constituciones de la República de Panamá. Panamá: Centro de Impresión Educativa.

Galindo Heurtematte, Mario. 1999. Entrevista personal, 4 de enero.

Guevara Mann, Carlos. 2001. "Forsaken Virtue: An Analysis of the Political Behavior of Panamanian Legislators, 1984-1999", tesis de grado para optar por el título de Doctor (PhD) en Gobierno y Relaciones Internacionales, University of Notre Dame.

Janson Pérez, Brittmarie. 1993. En nuestras voces: Panamá protesta, 1968-1989. Panamá: Editorial La Prensa.

Janson Pérez, Brittmarie. 2000. Entrevista por correo electrónico, 27 de noviembre.

Katz, Richard. 1980. A Theory of Parties and Electoral Systems. Baltimore: Johns Hopkins University Press.

Koster, Richard M. 2000. Entrevista por correo electrónico, 24 de octubre.

Koster, Richard M. y Sánchez Borbón, Guillermo. 1990. In the Time of the Tyrants: Panamá, 1968-1990. New York: W.W. Norton. La Estrella de Panamá, Diario, Panamá.

La Prensa, Diario, Panamá. Versión electrónica (www.prensa.com).

Labrut, Michele. 1982. Este es Omar Torrijos. Panamá: Edición de la autora.

Madison, James; Hamilton, Alexander; y Jay, John. 1987 [1787]. En The Federalist Papers, editado por Isaac Kramnick. Harmondsworth: Penguin. 
Mainwaring, Scott. 1999. Rethinking Party Systems in the Third Wave of Democratization: The Case of Brazil. Stanford: Stanford University Press.

Miró, Rodrigo. 1995. Sentido y misión de la historia en Panamá. Panamá: Biblioteca Cultural Shell.

Moscoso, Antonio, Carlos Cabezas, Rodolfo Aguilera. 1945. Segunda Asamblea Nacional Constituyente de la República Istmeña. Panamá: Edición de los autores.

Pereira, Renato. 1979. Panamá: fuerzas armadas y política. Panamá: Ediciones Nueva Universidad.

Pitkin, Hanna Fenichel. 1967. The Concept of Representation. Berkeley: University of California Press.

Pizzurno, Patricia y Celestino Andrés Araúz. 1996. Estudios sobre el Panamá republicano (1903-1989). Panamá: Ediciones Manfer.

Priestley, George. Military Government and Popular Participation in Panama: The Torrijos Regime, 1968-1975. Boulder: Westview Press, 1986.

República de Panamá. Asamblea Legislativa. Portal electrónico de la Asamblea Legislativa (www.asamblea.gob.pa).

República de Panamá. Asamblea Nacional de Panamá. 1948. "Resolución por la cual la Asamblea Nacional se declara Asamblea Constituyente." En Estudios Políticos 1 (Enero-marzo de 1998): 34-36.

República de Panamá. Ministerio de Economía y Finanzas. 2000. “Distribución de ingresos en Panamá". Ministerio de Economía y Finanzas (www.mef.gob.pa).

Ricord, Humberto E. 1999. Entrevista personal, 18 de agosto.

Sánchez Borbón, Guillermo. 1993. "Los partidos politicos". En Las elecciones de 1994: Panamá frente a su destino, editado por el Instituto Latinoamericano de Estudios Avanzados (ILDEA). Panamá: ILDEA.

Sánchez González, Salvador. 2004. “Cien años de labor legislativa”. En Historia General de Panamá Vol. 3, editado por Alfredo Castillero Calvo. Panamá: Comité Nacional del Centenario / UNESCO.

Still, Jonathan. 981. "Political Equality and Election Systems". Ethics 91: 375-394.

Valdés Escoffery, Eduardo. 2002. "Evolución de los sistemas electorales aplicados a la elección de legisladores en la República de Panamá". Trabajo presentado en el Primer Curso Internacional de Derecho Parlamentario, Panamá, 22-26 de julio (www.tribunal-electoral.gob.pa/publicaciones/publicaciones/documentos/folleto-mag-valdes.pdf).

Weber, Max. 1978 [1918]. "Parliament and Government in a Reconstructed Germany (A Contribution to the Political Critique of Officialdom and Party Politics)". En Max Weber, Economy and Society: An Outline of Interpretive Sociology, editado por Guenther Roth y Claus Wittich. Berkeley: University of California Press.

Weber, Max. 1946 [1919]. "Politics as a Vocation". En Max Weber, From Max Weber: Essays in Sociology, traducido y editado por H.H. Gerth and C. Wright Mills. New York: Oxford University Press.

Weber, Max. 1919. "La política como vocación”, Cátedra Rubinich, Universidad de la República, Buenos Aires, Argentina http://catedras.faoc.uba.ar/rubinich/awebl.html).

Carlos Guevara Mann es PhD de la Universidad de Notre Dame, 2001. Autor de Panamanian Militarism: A Historical Interpretation (Athens: Ohio University Press, 1996), publicado en español como llegitimidad y hegemonía: Una interpretación histórica del militarismo panameño (Panamá: Editorial La Prensa, 1994). Consultor, comentarista político y profesor universitario, ha sido Director General de Política Exterior y Secretario del Consejo Nacional de Relaciones Exteriores del Ministerio de Relaciones Exteriores y Director-Vocal del Comité Nacional del Centenario de Panamá.

(E-Mail: cguevara @nd.edu) 